\title{
Neurologists' detection and recognition of mental disorder in a tertiary in-patient neurological unit
}

\author{
Samr Dawood, ${ }^{1}$ Norman Poole, ${ }^{2}$ Robert Jr Fung, ${ }^{2}$ Niruj Agrawal ${ }^{2}$
}

BJPsych Bulletin (2018) 42, 19-23, doi:10.1192/bjb.2017.7

${ }^{1}$ Springfield University Hospital, South West London and St George's Mental Health NHS Trust, London; ${ }^{2}$ St George's Hospital, London

Correspondence to Samr Dawood (Samr.Dawood@swlstg-tr.nhs.uk) First received 13 Feb 2017, final revision 27 May 2017, accepted 29 Jun 2017

(c) The Authors 2018. This is an Open Access article, distributed under the terms of the Creative Commons Attribution licence (http://

creativecommons.org/licenses/by/ 4.0/), which permits unrestricted reuse, distribution, and reproduction in any medium, provided the original work is properly cited.
Aims and method Psychiatric disorders are common in neurological in-patients, but they are under-recognised and undertreated. We investigated the frequency of detection of mental disorder and referral to psychiatric services in a regional neuroscience centre. The results were compared with the expected prevalence. All in-patient referrals received in 2014 from the in-patient wards of the regional neuroscience centre and acute neurological unit were reviewed.

Results A total of 129 ward referrals were identified; of these, 78 were from the regional in-patient neurological unit, which comprised $11.4 \%$ of the total of 679 admissions to that unit.

Clinical implications A spectrum of neuropsychiatric conditions were recognised by neurologists, but overall rates of recognition were low. To address the problem of under-recognition, routine screening with validated assessment tools can represent a cost-effective and acceptable method to detect psychiatric disorders in an in-patient neurological setting.

Declaration of Interest None.
Liaison neuropsychiatry is an important element of psychiatric care in neurological in-patients, given the severity and complexity of the cases involved. ${ }^{1}$ Yet there is a dearth of information about consultation rates, presentation, diagnoses, and interventions that would improve access to services, facilitate evidence-based practice, and articulate the relationship between neurological and psychiatric disorders. $^{2-4}$

Previous estimates of psychiatric comorbidity in neurological settings have revealed high prevalence rates. For example, the overall rate of psychiatric disorder in neurological out-patient clinics has been reported as $55.1 \%,{ }^{5}$ the most frequent diagnoses being somatoform disorders, which represented $33.8 \%$ of the sample. Similarly, the prevalence in an acute in-patient neurological unit was $51.3 \%{ }^{6}$ It appears, therefore, that psychiatric comorbidity is high in neurological settings. This is to be expected, given the elevated rates of psychiatric comorbidity in neurological disorders. Patients with cerebrovascular and Parkinson's disease have prevalence of depression that ranges between 20 and $40 \%{ }^{7,8}$ Functional neurological symptoms are also common in neuroscience settings; it has been reported that $14 \%$ of consecutive neurological admissions had no so-called 'organic' bases for their symptoms, while another $24 \%$ had symptoms not fully accounted for by the underlying pathology. ${ }^{9}$

Neuropsychiatric conditions in neurological in-patients, if undetected or not adequately managed, are associated with poor quality of life, greater morbidity, mortality and poor psychosocial outcomes. ${ }^{10}$ Moreover, there are specific neuropsychiatric presentations associated with common neurological conditions that pose diagnostic, nosological and management challenges, which require the unique clinical skills of neuropsychiatrists. These conditions may include schizophrenia-like psychosis of epilepsy, forced normalisation, ${ }^{\text {ll }}$ organic personality changes or organic mood disorders, ${ }^{12}$ to name a few. This highlights the need for the development and implementation of structured care pathways for the neuropsychiatric comorbidities associated with neurological conditions. ${ }^{13}$

Despite these high rates of psychiatric comorbidity, surveys investigating referrals from neurology wards to neuropsychiatric liaison services have demonstrated unexpectedly low rates of referral. Fitzgerald et al and Jonge et al found that only $6 \%$ and $2.4 \%$ of neurology in-patients, respectively, were referred to liaison neuropsychiatry. ${ }^{14,15}$ The present study sought to investigate the rates of referral to an established neuropsychiatry service in a tertiary neurosciences centre, in order to better understand referral patterns and rates of recognition of mental disorder in neurological in-patients.

\section{Method}

This study was conducted at the Atkinson Morley Regional Neurosciences Centre at St George's Hospital, London, covering a population of 3 million residents of South West 
London and Surrey. All referrals made to the neuropsychiatry service at St George's Hospital over a 12-month period in 2014 were included.

We reviewed the referral forms and electronic patient records to extract information on demographics, reasons for referral, diagnoses, treatment plan, and number of contacts made. We identified the reasons for referral from the free text provided by the referrers. This requested information gives specific details about reasons for referral, presenting symptomology, referrers' suspected diagnoses, previous psychiatric history and interventions, and management difficulties. Reasons for referral were grouped into categories, and more than one reason for each patient was allowed. The patient electronic records system used to record every contact with patients was also searched to retrieve the primary ICD-10 diagnoses for each patient. These results were then compared against those available in the published literature on neuropsychiatry and adult liaison psychiatry services referral patterns.

Those referred to the neuropsychiatry service from the acute neurology ward were compared against admission data for that ward to establish rates of referral. This was then contrasted with results from previous studies of this ward investigating the prevalence and rate of detection of mental disorder by neurologists. All clinicians involved in this study work within the clinical team and had access to patients' records as part of their role. Anonymised data were analysed and compared with previously published data.

\section{Results}

A total of 129 referrals were identified in the year 2014. They were evenly dispersed across age groups, with a small peak in the age group 50-59. The female:male ratio for referral was 1.35:1 $(P=0.09)$. Almost $50 \%$ of the sample had a past psychiatric history. In terms of face-to-face contacts made, $32 \%$ received initial assessment only, $27 \%$ were seen twice, $15 \%$ were seen three times, and $10 \%$ were seen four times. The remaining $16 \%$ had four or more face-to-face contacts. The cumulative sum of all face-to-face contacts (first assessment and follow-up) was 311. Usually, the first assessments lasted 45-75 minutes and 90\% were seen within 2 working days of the date of referral. The highest rates of referral were during the months March, June, October and December.

Sixty per cent of referrals came from the regional in-patient neurology ward, $15 \%$ from neurosurgical wards, $9 \%$ from the stroke units, and $4 \%$ from the neuro-intensive care unit (NICU). The remainder were referred from other wards. Only $7 \%$ were made as urgent referrals. It was documented on $75 \%$ of forms that the referrer had discussed referral with the patient.

The most frequent cited reasons for referral were depression (50\%), functional neurological symptoms or functional overlay (27\%), anxiety (22\%), cognitive decline or confusion (17\%), agitation/aggression (13\%), suicidal ideation or behaviour (12\%), and psychotic symptoms (12\%). Often, more than one reason for referral was provided; hence, the percentages do not total $100 \%$. As a reason for referral, 'agitation' was associated most with organic disorders, 'suicidal' with adjustment disorder and organic mood disorder, and 'depression' with mood disorders, adjustment disorder and 'no diagnosis'. Functional symptoms/overlay were invariably associated with a psychiatric diagnosis of dissociative/conversion disorders. Almost all (91\%) of the referred patients met the criteria for a psychiatric disorder according to ICD-10. The most common primary psychiatric diagnoses were: mood disorder (22\%); dissociative disorder (18\%); adjustment disorder (9\%); delirium (5\%); organic disorders (24\%), including organic mood disorder (8.5\%); and organic personality disorder (5\%). In $9 \%$ of those referred, no mental disorder was established (Fig. 1).

Seventy-eight of the referrals were sent from the regional in-patient neurological unit, comprising $11 \%$ of the total of 679 admissions to that unit. The age of referred patients was distributed evenly across the decades of life, with a small peak in the $20-29$ age group. The female: male ratio was 1.4:1. Initial assessment only was completed for $31 \%$, while $27 \%$ were seen twice, $14 \%$ three times, and the remainder four times or more. Urgent referrals constituted $10 \%$ of all referrals from this ward, and $83 \%$ of referral forms had documented a discussion with the patient. Collectively, depression, anxiety and adjustment disorders represented the most frequent diagnoses (32\%), followed by 'organic' disorders (31\%) and then somatoform disorders (21\%). Most of those referred (81\%) had a past history of psychiatric disorder. The majority of those patients diagnosed with dissociative disorders (70\%) attended out-patient follow-up with our service following discharge.

\section{Discussion}

This is a retrospective study of referrals from a regional neurology unit, which can come with its own limitations. Such a unit would generally have more complex neurological in-patients with a higher rate of neuropsychiatric comorbidity. However, the results of the present study and previously published papers are broadly comparable, suggesting no specific biases associated with our study population. The total number of referrals was small, despite the expected prevalence of psychiatric illnesses in neurological settings. This is in keeping with the low rates of identification of psychiatric comorbidity found in earlier prevalence studies. It may also suggest that neurology colleagues have a high threshold for referral to the psychiatric services. However, this implies that patients suspected to have psychiatric disorder were not referred to specialist services.

Our results show that patients referred to the team presented with a wide range of neuropsychiatric disorders (Fig. 1). The rates of mental disorder in our sample did not match those in community ${ }^{16}$ or general hospital ${ }^{17}$ settings, demonstrating the distinctive nature of neuropsychiatric samples. The most common categories in our population were mood disorders, organic disorders and dissociative disorders, while the most common reasons for referrals were 'depression' and 'functional neurological symptoms'. Rates of disorder in our sample were close to those reported in previous studies, ${ }^{14,15}$ with a few differences. ${ }^{17}$ One difference is that depressive disorder accounted for $40 \%$ of referrals reported by Guthrie et al to their general liaison service that serves a large teaching hospital, but only 


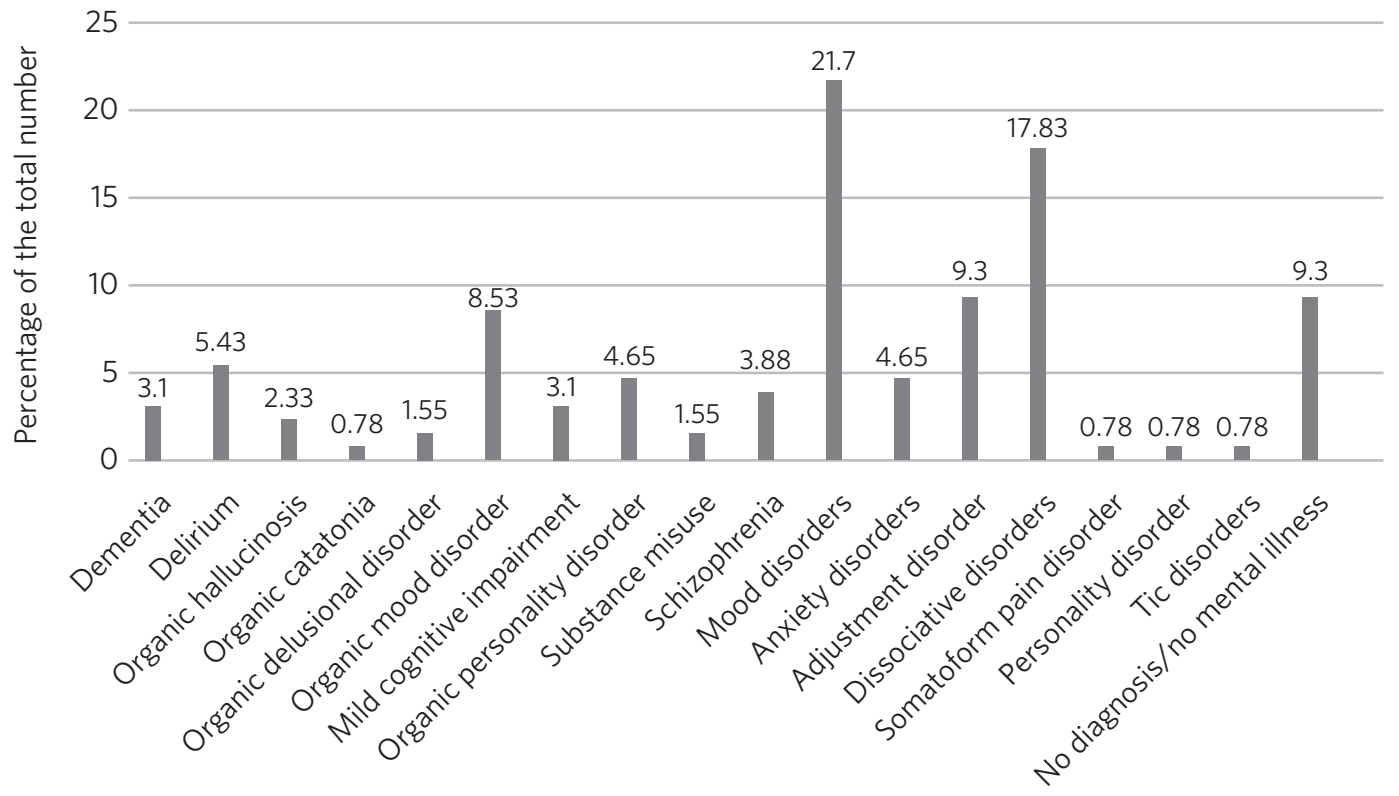

Diagnosis Categories

Fig. 1 Distribution of patients per diagnostic categories.

$20 \%$ of our referrals received this diagnosis. Nevertheless, as for Guthrie et al, 'depression' was the leading reason for referral to our service and the most common diagnosis in our sample. Schizophrenia and bipolar disorders constituted a small portion of our workload, while they comprised one-third for Guthrie et al. Other significant differences were found in the rates of somatoform disorders (18.6 v. 2.6), organic disorders (24 v. 1.7), substance use disorders (4.8 v. 1.55) and personality disorders (0.7 v. 3.8), as shown in Table 1. Not unexpectedly, perhaps, our neuropsychiatry team was referred a higher proportion of organic disorders compared with the general hospital liaison service of Guthrie et al. It might be that neurologists perceive neuropsychiatrists as more willing and/or able to manage patients with organic psychiatric disorders than a liaison psychiatric service, such as that of Fitzgerald et al. Alternatively, because the Atkinson Morley Centre is a tertiary unit which admits complex neurological cases, there may be a higher percentage of organic psychiatric disorder in the population we serve. Another difference was the higher rate of dissociative

\begin{tabular}{|c|c|c|c|c|}
\hline Diagnostic categories & $\begin{array}{l}\text { Jonge et al, } 2001 \\
\text { (neurological ward } \\
\text { referrals to general } \\
\text { liaison psychiatric } \\
\text { service) }\end{array}$ & $\begin{array}{c}\text { Fitzgerald et al, } 2008 \\
\text { (neurological ward } \\
\text { referrals to general } \\
\text { liaison psychiatric } \\
\text { service) }\end{array}$ & $\begin{array}{l}\text { Dawood et al, } 2016 \\
\text { (neurological ward } \\
\text { referrals to } \\
\text { neuropsychiatric } \\
\text { service) }\end{array}$ & $\begin{array}{c}\text { Guthrie et al, } 2016 \\
\text { (general non-neurological } \\
\text { ward referrals to general } \\
\text { liaison psychiatric } \\
\text { service) }\end{array}$ \\
\hline Diagnostic system & ICD-10 & DSM-IV & ICD-10 & ICD-10 \\
\hline Mood disorders & 15.1 & 24 & 21.7 & 46.5 \\
\hline $\begin{array}{l}\text { Somatoform disorder/dissociative disorders/ } \\
\text { Medically unexplained symptoms }\end{array}$ & 19.3 & 23 & 18.6 & 2.6 \\
\hline Anxiety disorders/adjustment disorders & 15.5 & 11 & 12.2 & 6.4 \\
\hline Organic disorders, including dementia & 16 & 5 & 24 & 5.2 \\
\hline Delirium & 3.8 & & 5.4 & 6.7 \\
\hline Substance use disorders & 4.4 & 20 & 1.55 & 4.7 \\
\hline Psychosis/schizophrenia & 2.7 & 5 & 3.9 & 14.8 \\
\hline Personality disorders & & & 0.77 & 3.8 \\
\hline Others & 7.9 & & 2.33 & 2 \\
\hline No mental illnesses/differed & 15.1 & 12 & 9.3 & 7.3 \\
\hline Total & 100 & 100 & 100 & 100 \\
\hline
\end{tabular}




\begin{tabular}{|c|c|c|c|}
\hline Diagnostic categories & Jefferies et al, 2007 & Earl et al, 2011 & Dawood et al, 2016 \\
\hline Diagnostic system & $\begin{array}{l}\text { Prevalence of psychiatric } \\
\text { diagnoses DSM-IV }\end{array}$ & $\begin{array}{c}\text { Psychiatric symptoms / } \\
\text { problems detected by neurologist }\end{array}$ & $\begin{array}{c}\text { Diagnoses referred by } \\
\text { neurologists, ICD-10 }\end{array}$ \\
\hline Mood disorders plus organic mood disorders & 24.8 & 9.2 & 3 \\
\hline Delirium, dementia and cognitive disorders & 17.7 & 6.7 & 0.88 \\
\hline Anxiety & 12.7 & 2.2 & 0.73 \\
\hline Adjustment disorders & 4.6 & 0 & 0.88 \\
\hline Somatoform disorders & 4.5 & 6.4 & 2.5 \\
\hline Substance use disorders & 3 & & 0.1 \\
\hline Personality disorders & 2 & & 0.29 \\
\hline Disorders usually diagnosed in childhood & 2 & & 0.1 \\
\hline Other disorders that may be of clinical importance & 2 & & 0 \\
\hline Psychotic disorders & 1 & 1.6 & 1 \\
\hline Eating disorders & 0.5 & & 0 \\
\hline Other organic disorders & & & 1.1 \\
\hline No diagnosis & & & 0.58 \\
\hline Total $^{a}$ & 51.1 & 23.7 & 11.16 \\
\hline
\end{tabular}

a. Percentages add up to more than total because some cases had two or more comorbid psychiatric diagnoses.

disorders compared with liaison psychiatry teams, which again likely reflects that a tertiary neurology centre admits the most complex functional cases for thorough investigation and intervention - especially as there is a dearth of neuropsychiatry services outside the London area. The unexpectedly low rate of substances misuse and personality disorders identified in our sample could reflect a reluctance to discuss these issues or an oddity of our population. Either way, this finding merits further evaluation. These variations will differentially influence the clinical expertise and practice of neuropsychiatrists and their colleagues in liaison psychiatry.

Regarding the acute in-patient neurological unit, our results demonstrated a referral rate of only $11.16 \%$, although previous studies on the same ward have demonstrated substantially higher prevalence rates. Utilising a battery of screening questionnaires followed by psychiatric interview Jeffries et $a l^{6}$ identified a DSM-IV-defined mental disorder in $51.3 \%$ of 265 consecutive admissions during a period of 6 months. Of these, $18.7 \%$ fulfilled the criteria for two diagnoses, and $5.1 \%$ were diagnosed with three or more. Earls et $a l^{18}$ investigated rates of detection of psychiatric symptoms by neurologists on this same ward 3 months pre and post Jeffries et al's screening period. This showed that neurologists recognised and documented symptoms of mental illnesses in $23.7 \%$ of all admissions, but referred fewer than half of these (10.4\%), echoing our more recent findings (11.6\%). Taken together, this demonstrates that $70-80 \%$ of neurological patients with a comorbid psychiatric disorder are not being referred to specialist services. Given the known impact of neuropsychiatric comorbidity on quality of life, duration of hospital stay, mortality, and cost of care, this may have a deleterious effect on those unable to access timely and effective psychiatric intervention. ${ }^{19}$ of those who were referred, analysis of the reason(s) for referral indicated strong correlation with the eventual confirmed diagnosis. The small number of patients who did not receive any diagnosis points to a low rate of false positives. Thus, it appears that neurology referrers were specific but not sensitive to identification of cases. Table 2 suggests that few patients with anxiety, adjustment disorders, personality disorders, and substance misuse disorders were referred, while referral was made for only a minority of those with depression and cognitive disorders. Appropriately, all those with psychotic disorders were referred, as were half the patients with somatoform disorders. Regarding patients with cognitive impairment, it may be that neurologists consider themselves capable of managing this patient group, as agitation was given as the main reason for the referral in all cases involving that problem.

It is unclear how this under-referral affects the wellbeing of patients and the efficiency of neurological departments. Similarly, Jonge et al found that neurologists throughout Europe refer only a small proportion of the psychiatric patients on their wards. Possibly, their recognition of mental disorder is poor, or these comorbidities are considered irrelevant to their neurological care. Jonge suggested a referral procedure consisting of a short questionnaire to facilitate detection of caseness. ${ }^{15}$ Likewise, Jeffries et al concluded that psychiatric screening questionnaires have a high sensitivity and specificity, thereby representing a costeffective and acceptable method for improving identification of psychiatric morbidity and comorbidity. ${ }^{6}$ The intervening years have not lessened the arguments for this approach. There is now a pressing need for strategic planning to develop neuropsychiatric provision, both nationally and internationally. ${ }^{20-22}$ Provision of prospective screening on neurological units and the impact of neuropsychiatric input would require prospective evaluation to evaluate their utility and efficacy. 


\section{Acknowledgements}

We would like to thank Ms. Olga Rak, Library Services Manager at Springfield University Hospital, and Ms. Rebecca Ewens, Team Administrator, Neuropsychiatry Service, St George's Hospital, for their support.

\section{About the authors}

Dr Samr Dawood, MBCHB, FICMS, MRCPsych, Higher Trainee in General Adult Psychiatry, Springfield University Hospital, South West London and St George's Mental Health NHS Trust, London, UK; Dr Norman Poole, MD, MRCPsych, MSc, Consultant Neuropsychiatrist, St George's Hospital, London, UK; Dr Robert Jr Fung, MRCPsych, Speciality Doctor in Neuropsychiatry in South West London and St George's Mental Health NHS Trust, St George's Hospital, London, UK; Dr Niruj Agrawal, MBBS, MD, MSc, Dip CBT, FRCPsych, Consultant Neuropsychiatrist and Honorary Senior Lecturer, St George's Hospital, London, UK.

\section{References}

1 Agrawal N, Mitchell AJ. The national service framework of long term conditions. BMJ 2005; 330: 1280-1.

2 Agrawal N, Fleminger S, Ring H, Deb S. Neuropsychiatry in the UK: planning the service provision for the 21st century. Psychiatr Bull 2008; 32: 303-6.

3 Agrawal N, Bhattacharya R, Rickard H. Provision of neuropsychiatry services: variability and unmet need. BJPsych Bull 2015; 39(6): 297-301.

4 Arambepola NMA, Rickards H, Cavanna AE. The evolving discipline and services of neuropsychiatry in the United Kingdom. Acta Neuropsychiatr 2012; 24: 1-8.

5 Fink P, Hansen MS, Søndergaard L, Frydenberg M. Mental illness in new neurological patients. J Neurol Neurosurg Psychiatry 2003; 74: 817-9.

6 Jefferies K, Owino A, Rickards H, Agrawal N. Psychiatric disorders in in-patients of a neurology ward: estimate of prevalence and usefulness of screening questionnaires. J Neurol Neurosurg Psychiatry 2007; 78 : 414-6.

7 Robinson RG, Spalletta G. Post-stroke depression: a review. Can J Psychiatry 2010; 55: 341-9.

8 Frisina PG, Borod JC, Foldi NS, Tenenbaum HR. Depression in Parkinson's disease: health risks, etiology, and treatment options. Neuropsychiatr Dis Treat 2008; 4: 81-91.
9 Ewald $\mathrm{H}$, Rogne $\mathrm{T}$, Ewald $\mathrm{K}$, Fink $\mathrm{P}$. Somatisation in patients newly admitted to a neurology department. Acta Psychiatrica Scand 1994; 89: 174-9.

10 Ayerbe L, Ayis S, Wolfe CD, Rudd AG. Natural history, predictors and outcomes of depression after stroke: systematic review and meta-analysis. Br J Psychiatry 2013; 202(1): 14-21.

11 Trimble MR. Epilepsy and psychiatric disorders. Acta Neuropsychiatrica 1999; 11(04): 137-40.

12 Rudolph JL, Fonda JR, Hunt PR, McGlinchey RE, Milberg WP, Reynolds MW, et al. Association of pseudobulbar affect symptoms with quality of life and healthcare costs in veterans with traumatic brain injury. J Affect Disord 2016; 190: 150-5

13 Osman A, Seri S, Cavanna AE. Clinical characteristics of patients with epilepsy in a specialist neuropsychiatry service. Epilepsy Behav 2016; 58: $44-7$.

14 Fitzgerald P, Herlihy D, Sweeney B, Cassidy EM. Neurology referrals to a liaison psychiatry service. Ir Med J 2008; 101(9): 271-3.

15 Jonge $\mathrm{P}$, Huyse FJ, Herzog $\mathrm{T}$, et al. Referral pattern of neurological patients to psychiatric consultation-liaison services in 33 European hospitals. Gen Hosp Psychiatry 2001; 23: 152-7.157.

16 Mclenan J, Lazzari C, Mcmillan G, Mackie R. psychopathology of the general population referred by primary care physicians for urgen assessment in psychiatric hospitals. Ir J Psychiatry 2016; 11(4): 201-205.

17 Guthrie E, McMeekin A, Thomasson R, Khan Y, Makin S. Opening the 'black box': liaison psychiatry services and what they actually do. BJPsych Bull 2016; 40(4): 175-180

18 Earl J, Pop O, Jefferies K, Agrawal N. Impact of neuropsychiatry screening in neurological in-patients: comparison with routine clinical practice. Acta Neuropsychiatr 2011; 23(6): 297-301.

19 Dilley $M$, Fleminger S. Advances in neuropsychiatry: clinical implications. Adv Psychiatr Treat 2005; 12(1): 23-34

20 Sachdev P. An agenda for neuropsychiatry as a 21st century discipline. Acta Neuropsychiatr 2007; 19: 2-5.

21 Agrawal N. Development of neuropsychiatry services worldwide. Acta Neuropsychiatr 2012; 24: 189-90.

22 Sachdev P. Guest editorial: International Neuropsychiatric Association. Neuropsychiatr Dis Treat 2005; 1: 191-2. 